\title{
Aortic Dissection
}

\author{
Jayesh V Trivedi* \\ Head of department and professor of medicine, Gujarat adani institute of medical science, India
}

Received: August 23, 2017; Published: September 08, 2017

*Corresponding author: Jayesh V Trivedi, Head of department and professor of medicine, Gujarat adani institute of medical science, Bhuj, Gujarat, India, Tel: 9824076530; Email: drjvtrivedi@rediffmail.com

\section{Mini Review}

Aortic dissection occurs in 3 in 100,000 people per year. Tear in the inner side of aorta causes blood to flow between layers of aorta causing seperation of media layer into inner two third and outer one third. Dissection can be antegrade or retrograde.

\section{Symptoms}

$96 \%$ of people will have chest pain with varying severity with or without radiation. Back pain, vomiting, sweating, headache, blood stained diarrhea, paralytic ileus, strokes and death Males are more affected than females. Males will have double incidence as females.

\section{Aetiology}

Hypertensions in $80 \%$ of patients were observed. A connective tissue disorder is also common. Bicuspid Aortic valve is seen in 7to $14 \%$ of patients. 5To9\% of patients has Marfan syndrome. Along with this Atherosclerosis, Trauma, Post cardiac surgery, Smoking, Cocaine abusers, pregnancy, Aortoarteritis, Turners syndrome, High intensity weightlifting, Syphilis are the other causes [1-7].

\section{Diagnosis}

D dimer more than $500 \mathrm{ng} / \mathrm{ml}$ rules out Aortic dissection. Transoesophageal echocardiogram helps in diagnosing the sensitivity is $98 \%$ and specificity is $97 \%$. Ultrasound of abdomen, computerized Tomography, Magnetic resonant Angiography will diagnose Aortic dissection, the sensitivity is $98 \%$ and specificity is $98 \%$. This is being classified in to Stanford Type A. Where ascending and arch of aortas are affected. Stanford Type B...where ascending aorta is spared.

It is also classified in De Bakey classification as

A. Type 1. Dissection originates in ascending aorta. It occurs in patients less than 65 yrs of age.

B. Type 2. Dissction originates in ascending aorta and extends distally.

C. Type 3.Dissection occurs in descending aorta and rarely extends. This is commonly seen in patient having Hypertension and Atherosclerosis.

\section{Management}

Control Hypertension by either Betablockers, sodium nitroprusside, Calcium channel blockers like Diltiazem or verapamil, nonpyridine calcium channel blockers. Target mean arterial blood pressure should be 60 to $75 \mathrm{~mm}$ of hg. Initial decrease should be about $20 \%$. Patient emotional care and reduction in psychological stress is equally important along with medical treatment. Surgical treatment either Endovascular or open surgery may be necessary in acute emergencies (Figures 1-5).

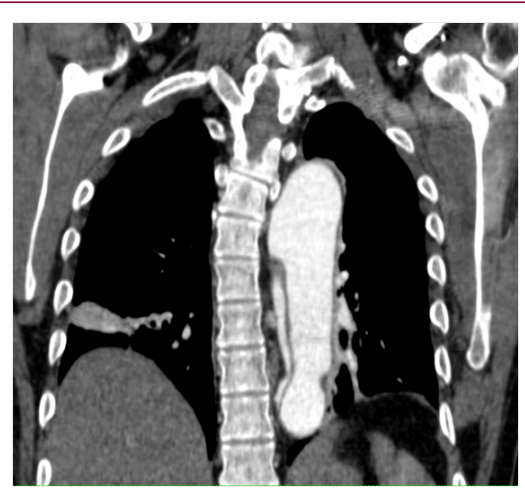

Figure 1: Severe hypotension in acute dissection indicates grave prognosis.

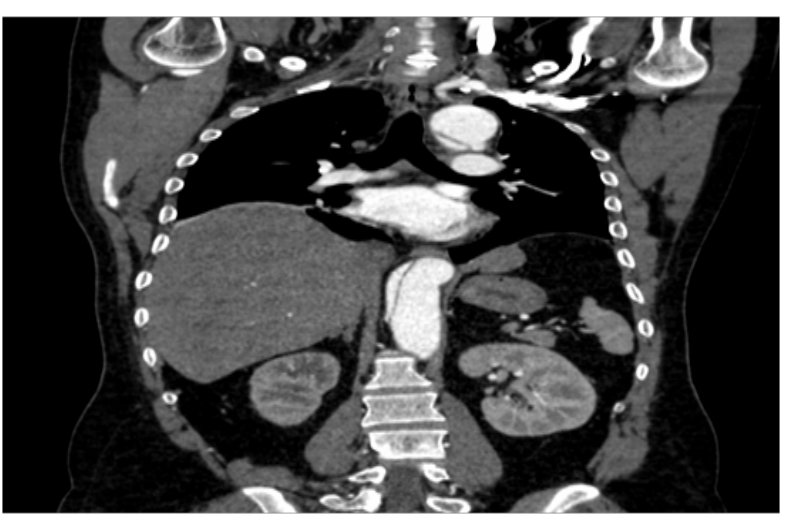

Figure 2: Aortic Dissection in Descending Aorta. 


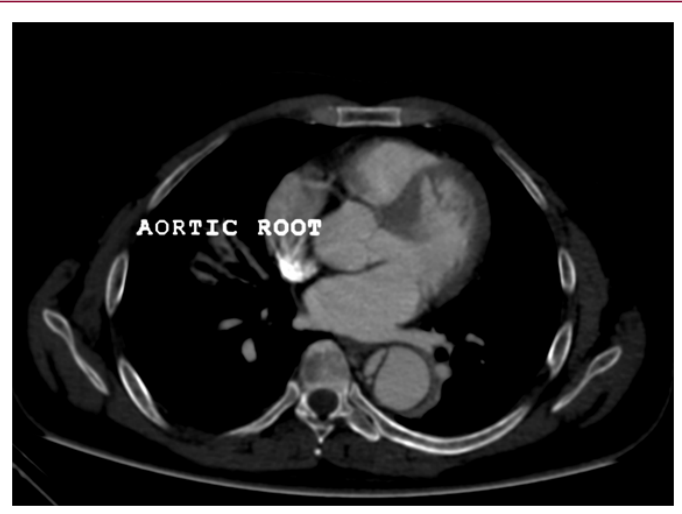

Figure 3: Aortic Dissection In Descending Aorta.

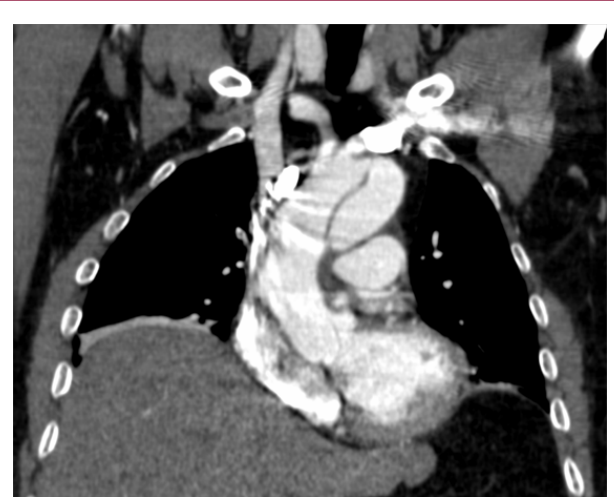

Figure 4: Dissction Ao Root.

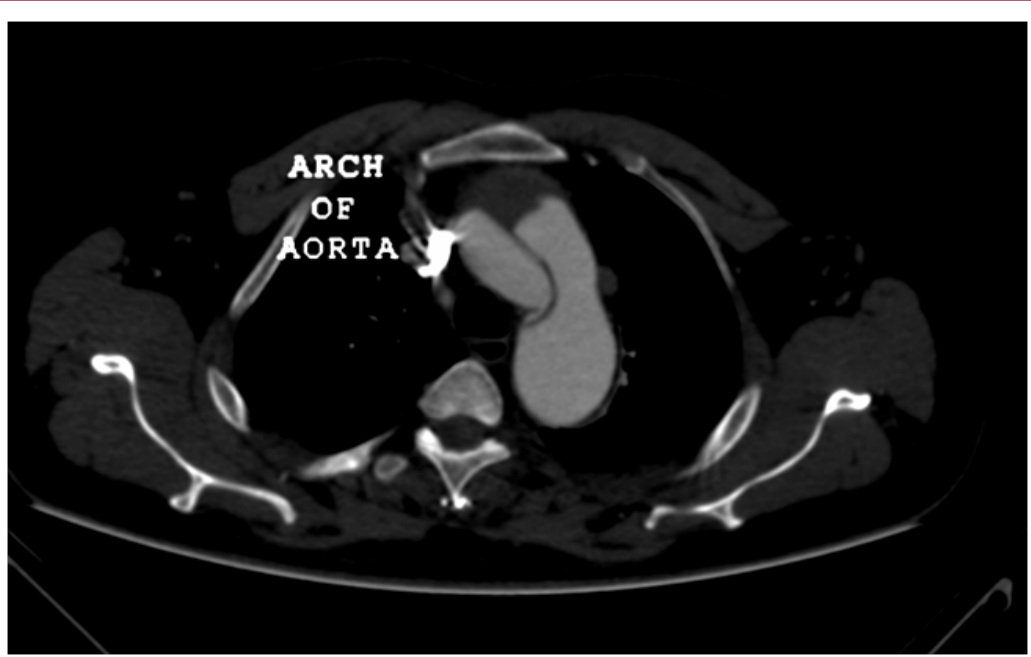

Figure 5: Dissection in Ascending Aorta And Arch Of Aorta.

\section{Prevention}

Tight Bp controls, avoid smoking, maintain ideal weight, wear a suit belt, regular medical checkup and control of dyslipidemia are important. Severe hypotension in acute dissection indicates grave prognosis.

\section{References}

1. Wojnarski CM, Svensson LG, Roselli EE, Idrees JJ, Lowry AM, et al. (2015) Aortic dissection in patients with bicuspid aortic valve-associated aneurysms. Ann Thorac Surg 100 (5): 1666-1673.

2. Benjamin MM, Roberts WC (2012) Fatal aortic rupture from nonpenetrating chest trauma. Proc Bayl Univ Med Cent 25(2): 121-123.

3. Jansen Klomp WW, Brandon Bravo Bruinsma GJ, Peelen LM, Nierich AP, Grandjean JG, et al. (2016) Clinical recognition of acute aortic dissections: insights from a large single-centre cohort study. Neth Heart J 25(3): 200-206.

4. Wang GX, Hedgire SS, Le TQ, et al. (2016) MR angiography can guide ED management of suspected acute aortic dissection. Am J Emerg Med.

5. Guideline Jacobs JE, Latson Jr LA, Abbara S, et al. Acute chest pain suspected aortic dissection. ACR American College of Radiology

6. Chaikof EL, Mutrie C, Kasirajan K, Milner R, Chen EP, et al. (2009) Endovascular repair for diverse pathologies of the thoracic aorta: an initial decade of experience. J Am Coll Surg 208 (5): 802-816.

7. Cooper M, Hicks C, Ratchford EV, Salameh MJ, Malas M (2016) Diagnosis and treatment of uncomplicated type B aortic dissection. Vasc Med 21 (6): 547-552.

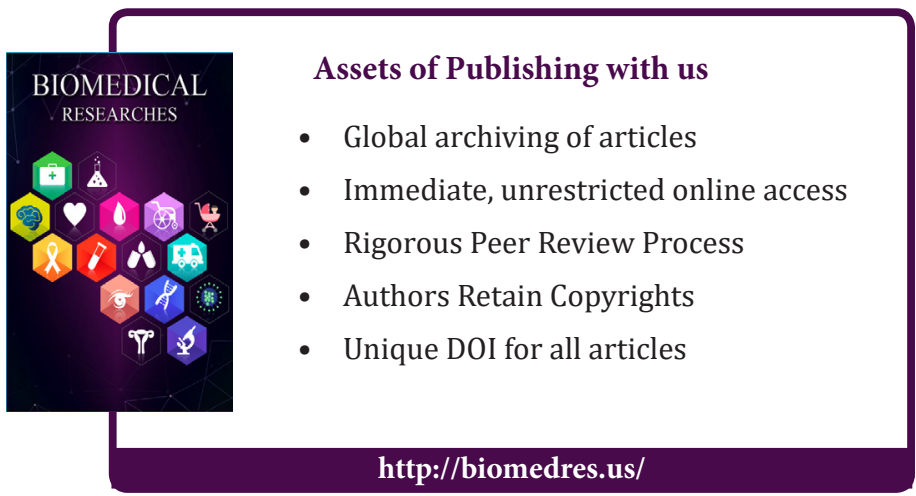

